\title{
Impact of preoperative extracorporeal membrane oxygenation on vasoactive inotrope score after implantation of left ventricular assist device
}

\author{
Takuma Maeda ${ }^{1,3^{*}}$, Koichi Toda ${ }^{2}$ Masataka Kamei ${ }^{1}$, Shigeki Miyata ${ }^{3}$ and Yoshihiko Ohnishi ${ }^{1}$
}

\begin{abstract}
The purpose of this study was to elucidate the difference in inotrope use between patients who underwent left ventricular assist device (LVAD) implantation with preoperative extracorporeal membrane oxygenation (ECMO) and those who underwent LVAD implantation without preoperative ECMO. One hundred and eight patients who underwent LVAD implantation were enrolled in this study. Prior to LVAD implantation, 27 patients received ECMO support (ECMO group) and the other 81 patients did not (non-ECMO group). Cardiac index (Cl), mean arterial pressure (MAP), mixed venous oxygen saturation (SvO2), and the vasoactive inotropic score (VIS) were recorded at weaning from cardiopulmonary bypass (CPB), 30 min after weaning from CPB (min after CPB), 60 min after CPB, and at the end of surgery. MAP and VIS were also recorded before induction of anesthesia (baseline). The modified VIS was defined as: (dopamine $\mu \mathrm{g} / \mathrm{kg} / \mathrm{min} \times 1+$ dobutamine $\mu \mathrm{g} / \mathrm{kg} / \mathrm{min} \times 1+$ epinephrine $\mu \mathrm{g} / \mathrm{kg} / \mathrm{min} \times 100+$ noradrenaline $\mu \mathrm{g} /$ $\mathrm{kg} / \mathrm{min} \times 100+$ milrinone $\mu \mathrm{g} / \mathrm{kg} / \mathrm{min} \times 10+$ olprinone $\mu \mathrm{g} / \mathrm{kg} / \mathrm{min} \times 25)$. There were no significant differences between the ECMO group and the non-ECMO group in terms of hemodynamic parameters such as MAP, $\mathrm{Cl}$, and $\mathrm{SvO}_{2}$. However, the ECMO group had higher VIS and noradrenaline doses than that of non-ECMO group ( $p=0.030$ and $p=0.044$, respectively). VIS was significantly higher in ECMO group at 30 min after CPB $(p=0.03), 60$ min after CPB $(p=0.003)$, and at the end of the surgery $(p<0.001)$. The doses of noradrenaline were significantly higher in ECMO group at 60 min after CPB $(p=0.013)$, and at the end of surgery $(p=0.002)$. Patients who received ECMO support prior to LVAD implantation required significantly more noradrenaline to maintain normal levels of hemodynamic parameters compared with patients without ECMO.
\end{abstract}

Keywords: Ventricular assist device, Inotrope score, Systemic inflammatory response, Vasopressor

\section{Background}

Mechanical circulatory support with left ventricular assist devices (LVADs) is becoming increasingly important as a therapeutic intervention for patients with advanced heart failure recalcitrant to medical therapy. It is important to set up patients eligible for transplantation with appropriate hemodynamic support without delay; otherwise death or serious morbidity may occur.

\footnotetext{
*Correspondence: takuma@ncvc.go.jp

${ }^{1}$ Department of Anesthesiology, National Cerebral and Cardiovascular

Center, 5-7-1 Fujishirodai, Suita, Osaka 565-8565, Japan

Full list of author information is available at the end of the article
}

Several risk factors have been identified in regard to mortality after LVAD implantation (Holman et al. 2009; Rao et al. 2003). One of the most significant risk factors is preoperative cardiogenic shock. Extracorporeal membrane oxygenation (ECMO) is often used to improve and stabilize the preoperative condition of LVAD patients. However, ECMO support prior to LVAD implantation has recently been reported to significantly worsen survival rates (Toda et al. 2012). ECMO has also been associated with systemic inflammatory response (SIRS) (Chen et al. 2013; Mc et al. 2010). Hence, we hypothesized that patients who receive ECMO support prior to LVAD implantation need higher doses of inotropes than

\section{Springer}


those without ECMO. The aim of this study was to elucidate the difference in inotrope use between patients who receive ECMO support prior to LVAD implantation and those who do not using the vasoactive inotropic score (VIS).

\section{Methods}

Approval for this study was obtained from the ethics committee at our institution, which waived the requirement for written informed consent from each patient because the retrospective registry involves no additional risk to the subjects. We retrospectively investigated 108 patients with advanced heart failure who underwent LVAD implantation as a bridge to heart transplantation at the National Cerebral and Cardiovascular Center between May 1999 and September 2011. We excluded two patients who underwent right ventricular assist device implantation. Four patients whose ECMO could not be removed during weaning from cardiopulmonary bypass $(\mathrm{CPB})$ were excluded as well because the cardiac index $(\mathrm{CI})$ and mixed venous oxygen saturation (SvO2) would be inaccurate in these patients. Anesthesia was induced with midazolam and fentanyl, and rocuronium was given to facilitate orotracheal intubation with a cuffed tube. Anesthesia was maintained in all patients with propofol and fentanyl or remifentanil. All patients were catheterized with Swan-Ganz catheters capable of automatically and continuous measurement of cardiac output and $\mathrm{SvO} 2$. Inotropes, vasopressors, and vasodilators are administered at the discretion of the individual attending anesthesiologist, depending on the hemodynamics. The target MAP was around $60-70 \mathrm{~mm} \mathrm{Hg}$, and the target CI was $2.0-2.5$. There were 27 patients who received ECMO support prior to LVAD implantation. ECMO consisted of a membrane oxygenator and a centrifugal pump (Capiox, Terumo, Tokyo, Japan). We defined these 27 patients as the ECMO group, and the other 81 patients as the non-ECMO group.

The patients' clinical data were collected from clinical records including demographics, preoperative laboratory data, and intraoperative variables. $\mathrm{CI}$, mean arterial pressure (MAP), systemic vascular resistance index (SVRI), $\mathrm{SvO} 2$, and VIS were recorded at weaning from $\mathrm{CPB}$, 30 min after weaning from $\mathrm{CPB}$ (min after $\mathrm{CPB}$ ), 60 min after $\mathrm{CPB}$, and at the end of the surgery. MAP and VIS were also recorded before induction of anesthesia (baseline).

We used a modification of the VIS described by Gaies et al. (2010). We expanded this formula to include the inotrope olprinone, which is a phosphodiesterase 3 inhibitor widely used in Japan; we chose 25 as its coefficient because the ratio of maintenance infusion of milrinone $(0.25 \mu \mathrm{g} / \mathrm{kg} / \mathrm{min})$ was compared with that of olprinone
$(0.1 \mu \mathrm{g} / \mathrm{kg} / \mathrm{min})$ in a previous report (Orime et al. 1999). Additionally, Milrila ${ }^{\circledR} \mathrm{K}$ (Astellas, Tokyo, Japan) specifies a maintenance dose range of $0.25-0.75 \mu \mathrm{g} / \mathrm{kg} / \mathrm{min}$, whereas Coretec ${ }^{\circledR}$ (Eisai, Japan) lists the range as 0.1$0.3 \mu \mathrm{g} / \mathrm{kg} / \mathrm{min}$; therefore, we concluded that a coefficient for olprinone 2.5 times that of milrinone was appropriate.

The modified VIS was defined as: (dopamine $\mu \mathrm{g} / \mathrm{kg}$ / $\min \times 1+$ dobutamine $\mu \mathrm{g} / \mathrm{kg} / \mathrm{min} \times 1+$ epinephrine $\mu \mathrm{g} /$ $\mathrm{kg} / \mathrm{min} \times 100+$ noradrenaline $\mu \mathrm{g} / \mathrm{kg} / \mathrm{min} \times 100+$ milrinone $\mu \mathrm{g} / \mathrm{kg} / \mathrm{min} \times 10+$ olprinone $\mu \mathrm{g} / \mathrm{kg} / \mathrm{min} \times 25$ ).

\section{Types of LVAD and surgical technique}

All surgical procedures were performed through a median sternotomy during $\mathrm{CPB}$. The outflow cannula was anastomosed to the ascending aorta and the inflow cannula to the left ventricular apex, without arresting the heart, to minimize ischemic insult to the right ventricle. The LVAD was then placed between the inflow and outflow cannulae (Toda et al. 2012). The LVADs comprised 91 paracorporeal devices (Toyobo-VAS: Nipro), and 17 implantable devices (two DuraHeart [Terumo]; two HeartMate VE [Thoratec]; four Novacor [World Heart]; seven Evaheart [Sun Medical]; one Jarvik 2000 [Jarvik Heart]; and one HeartMate II [Thoratec]).

\section{Statistical analysis}

To determine the required sample size, we estimated the expected difference in the mean VISs as eight, and the expected standard deviation as 12 . A power of 0.8 and an $\alpha$ of 0.05 were used to determine that 24 patients in the ECMO group would be appropriate. Hemodynamic data, VIS, and each inotrope dose were subjected to repeatedmeasures ANOVA. If the difference between the groups was significant, an independent $t$ test was used to determine the difference at each time point.

Statistical significance was set at a level of 0.05. All statistical analyses were performed with EZR (Saitama Medical Center, Jichi Medical University, Saitama, Japan), which is a graphical user interface for $\mathrm{R}$ ( $\mathrm{R}$ Foundation for Statistical Computing, Vienna, Austria). More precisely, it is a modified version of an $\mathrm{R}$ commander designed to add statistical functions frequently used in biostatistics (Kanda 2013).

\section{Results}

Table 1 shows the demographic data of all patients. Preoperative variables and intraoperative characteristics in the ECMO group and the non-ECMO group are shown in Table 2. There were no significant differences between groups in sex, age, body surface area, body mass index, aspartate aminotransferase, alanine aminotransferase, serum B-type natriuretic peptide level, anesthesia time, operation time, $\mathrm{CPB}$ time, and blood loss. However, a 
Table 1 Preoperative patient characteristics

\begin{tabular}{ll}
\hline Characteristic & Number or mean \pm SD \\
\hline Sex (M/F) & $76 / 32$ \\
Age (year) & $34.6 \pm 12.8$ \\
BSA (m²) & $1.55 \pm 0.20$ \\
BMI (kg/m ${ }^{2}$ ) & $19.4 \pm 3.7$ \\
Serum total bilirubin (mg/dl) & $2.3 \pm 2.3$ \\
Serum creatinine (mg/dl) & $1.4 \pm 1.1$ \\
Serum BNP (pg/ml) & $1436 \pm 994$ \\
Preoperative IABP support & $64(59.3)$ \\
Preoperative ECMO & $27(25.0)$ \\
LVEDD (mm) & $73 \pm 11$ \\
LVESD (mm) & $66 \pm 11$ \\
LVEF (\%) & $17 \pm 9$ \\
\hline
\end{tabular}

Data are presented as mean $\pm S D$, or number (\%)

$B S A$ body surface area, $B M I$ body mass index, $B N P$ brain natriuretic peptides, $I A B P$ intra-aortic balloon pump, ECMO extracorporeal membrane oxygenation, $\angle V E D D$ left ventricular end-diastolic diameter, LVESD left ventricular end-systolic diameter, LVEF left ventricular ejection fraction larger number of patients in the ECMO group required preoperative intra-aortic balloon pump support, mechanical ventilation, and intraoperative nitric oxide use. Serum total bilirubin, serum creatinine, and serum blood urea nitrogen (BUN) were significantly higher in the ECMO group. White blood cell count and C-reactive protein levels before LVAD implantation were significantly higher in the ECMO group. Hemoglobin, platelet count, serum total protein, and albumin levels were significantly lower in the ECMO group.

There was no significant difference between the group in terms of baseline MAP $(70.6 \pm 15.0 \mathrm{~mm} \mathrm{Hg}$ in the ECMO group, $67.8 \pm 14.0 \mathrm{~mm} \mathrm{Hg}$ in the non-ECMO group, $p=0.395)$. The hemodynamic changes in both groups are shown in Table 3. There were no significant differences between the ECMO group and the non-ECMO group in terms of hemodynamic parameters such as MAP, CI, SVRI, and $\mathrm{SvO}_{2}$. However, changes in the VIS were significantly different between groups (Table $4, p=0.030$ ). Each dose of inotrope was compared by repeated-measures ANOVA, which revealed that only the noradrenaline dose

Table 2 Preoperative variables and intraoperative characteristics in both groups

\begin{tabular}{|c|c|c|c|}
\hline & ECMO group $(n=27)$ & Non-ECMO group $(n=81)$ & $p$ value \\
\hline Sex (male) & $19(70.4)$ & $57(70.4)$ & 1.000 \\
\hline Age (year) & $33.4 \pm 12.4$ & $35.0 \pm 13.0$ & 0.573 \\
\hline $\mathrm{BSA}\left(\mathrm{m}^{2}\right)$ & $1.53 \pm 0.18$ & $1.56 \pm 0.21$ & 0.593 \\
\hline $\mathrm{BMI}\left(\mathrm{kg} / \mathrm{m}^{2}\right)$ & $18.6 \pm 2.7$ & $19.6 \pm 3.9$ & 0.216 \\
\hline Preoperative IABP support & $24(88.9)$ & $40(49.4)$ & $<0.001$ \\
\hline Preoperative mechanical ventilation & $22(81.5)$ & $7(8.6)$ & $<0.001$ \\
\hline White blood cell count $(/ \mathrm{ml})$ & $8580 \pm 2961$ & $10,789 \pm 4706$ & 0.006 \\
\hline Hemoglobin (g/dl) & $10.2 \pm 1.8$ & $11.3 \pm 1.9$ & 0.009 \\
\hline Platelet count $\left(\times 10^{4} / \mathrm{ml}\right)$ & $13.0 \pm 7.9$ & $24.4 \pm 24.4$ & 0.022 \\
\hline C-reactive protein (mg/dl) & $6.1 \pm 4.6$ & $3.1 \pm 3.3$ & $<0.001$ \\
\hline Serum total bilirubin (mg/dl) & $3.7 \pm 3.8$ & $1.9 \pm 1.3$ & $<0.001$ \\
\hline Serum total protein ( $\mathrm{g} / \mathrm{dl})$ & $6.0 \pm 0.7$ & $6.4 \pm 0.7$ & 0.015 \\
\hline Serum albumin (g/dl) & $3.3 \pm 0.7$ & $3.6 \pm 0.5$ & 0.010 \\
\hline AST (IU/L) & $243 \pm 507$ & $124 \pm 315$ & 0.157 \\
\hline $\operatorname{ALT}(I U / L)$ & $182 \pm 350$ & $178 \pm 392$ & 0.959 \\
\hline Serum creatinine $(\mathrm{mg} / \mathrm{dl})$ & $1.9 \pm 1.8$ & $1.2 \pm 0.7$ & 0.006 \\
\hline Serum BUN (mg/dl) & $40 \pm 26$ & $29 \pm 19$ & 0.024 \\
\hline Serum BNP (pg/ml) & $1380 \pm 985$ & $1453 \pm 1003$ & 0.772 \\
\hline Anesthesia time (min) & $522 \pm 140$ & $511 \pm 169$ & 0.767 \\
\hline Operation time (min) & $423 \pm 132$ & $398 \pm 151$ & 0.444 \\
\hline CPB time (min) & $161 \pm 60$ & $156 \pm 59$ & 0.689 \\
\hline NO use in operation & $16(59.3)$ & $25(30.9)$ & 0.008 \\
\hline Blood loss (ml) & $3054 \pm 3010$ & $2177 \pm 2188$ & 0.114 \\
\hline
\end{tabular}

Data are presented as mean $\pm \mathrm{SD}$, or number (\%)

ECMO extracorporeal membrane oxygenation, $B S A$ body surface area, $B M I$ body mass index, IABP intra-aortic balloon pump, $A S T$ aspartate aminotransferase, $A L T$ alanine aminotransferase, $B U N$ blood urea nitrogen, $B N P$ brain natriuretic peptides, $C P B$ cardiopulmonary bypass, $N O$ nitric oxide 
Table 3 Hemodynamic changes in both groups

\begin{tabular}{|c|c|c|c|c|c|c|}
\hline & Group & End of CPB & 30 min after $C P B$ & 60 min after CPB & End of surgery & $p$ value $^{\mathrm{a}}$ \\
\hline \multirow[t]{2}{*}{ MAP $(\mathrm{mm} \mathrm{Hg})$} & Non-ECMO group & $66.4 \pm 11.5$ & $70.7 \pm 12.2$ & $72.5 \pm 9.8$ & $74.1 \pm 16.2$ & 0.295 \\
\hline & ECMO group & $68.8 \pm 10.1$ & $68.3 \pm 13.2$ & $68.4 \pm 13.4$ & $70.1 \pm 11.5$ & \\
\hline \multirow[t]{2}{*}{$\mathrm{Cl}\left(\mathrm{L} / \mathrm{min} / \mathrm{m}^{2}\right)$} & Non-ECMO group & $2.5 \pm 0.9$ & $2.4 \pm 1.1$ & $2.5 \pm 0.8$ & $2.6 \pm 0.6$ & 0.989 \\
\hline & ECMO group & $2.2 \pm 1.3$ & $2.4 \pm 0.6$ & $2.4 \pm 0.5$ & $2.6 \pm 0.6$ & \\
\hline \multirow[t]{2}{*}{ SVRI (dynes s/cm $/ \mathrm{m}^{2}$ ) } & Non-ECMO group & $2120 \pm 945$ & $2139 \pm 822$ & $2214 \pm 803$ & $2082 \pm 777$ & 0.808 \\
\hline & ECMO group & $2489 \pm 844$ & $2197 \pm 670$ & $2184 \pm 898$ & $1962 \pm 518$ & \\
\hline \multirow[t]{2}{*}{$\mathrm{SvO}_{2}(\%)$} & Non-ECMO group & $78.2 \pm 8.7$ & $75.3 \pm 13.3$ & $74.8 \pm 7.5$ & $73.8 \pm 8.3$ & 0.120 \\
\hline & ECMO group & $73.6 \pm 13.7$ & $70.0 \pm 12.2$ & $69.9 \pm 9.2$ & $68.2 \pm 8.4$ & \\
\hline
\end{tabular}

Data are presented as mean $\pm \mathrm{SD}$

$C P B$ cardiopulmonary bypass, MAP mean arterial pressure, $\mathrm{Cl}$ cardiac index, SVRI systemic vascular resistance index, $\mathrm{SvO}_{2}$ mixed venous oxygen saturation, $E C M O$ extracorporeal membrane oxygenation

a compared between the two groups

Table 4 Change in vasoactive inotrope score and catecholamine dose in both groups

\begin{tabular}{|c|c|c|c|c|c|c|c|}
\hline & Group & Baseline & End of CPB & 30 min after CPB & 60 min after $C P B$ & End of surgery & $p$ value $^{\mathrm{a}}$ \\
\hline \multirow[t]{2}{*}{ VIS } & Non-ECMO group & $13.2(5.7-16.0)$ & $22.1(9.4-23.0)$ & $16.8(8.7-20.0)$ & $16.3(9.5-17.5)$ & $14.7(8.8-16.6)$ & 0.030 \\
\hline & ECMO group & $13.4(8.1-16.0)$ & $24.9(12.7-26.4)$ & $24.7(12.1-25.3)$ & $26.1(12.3-33.3)$ & $25.5(12.7-31.7)$ & \\
\hline \multirow[t]{2}{*}{$\mathrm{DOA}(\mu \mathrm{g} / \mathrm{kg} / \mathrm{min})$} & Non-ECMO group & $3.3(0-5.0)$ & $3.8(3.0-5.0)$ & $3.8(3.0-5.0)$ & $3.8(3.0-5.0)$ & $3.8(3.0-5.0)$ & 0.250 \\
\hline & ECMO group & $3.4(1.8-4.9)$ & $4.1(3.0-5.0)$ & $4.3(3.3-5.0)$ & $4.2(3.0-5.0)$ & $4.0(3.0-5.0)$ & \\
\hline \multirow[t]{2}{*}{ DOB ( $\mu \mathrm{g} / \mathrm{kg} / \mathrm{min})$} & Non-ECMO group & $5.3(3.5-7.0)$ & $2.0(0-3.5)$ & $2.2(0-3.9)$ & $2.2(0-4.0)$ & $2.6(0-4.4)$ & 0.908 \\
\hline & ECMO group & $5.0(3.8-6.5)$ & $2.2(0-4.5)$ & $2.3(0-4.8)$ & $2.2(0-4.3)$ & $2.5(0-4.3)$ & \\
\hline \multirow[t]{2}{*}{$\operatorname{NAD}(\mu \mathrm{g} / \mathrm{kg} / \mathrm{min})$} & Non-ECMO group & $0.02(0-0)$ & $0.10(0-0.12)$ & $0.08(0-0.1)$ & $0.07(0-0.08)$ & $0.05(0-0.05)$ & 0.044 \\
\hline & ECMO group & $0.03(0-0)$ & $0.14(0-0.13)$ & $0.14(0-0.15)$ & $0.15(0-0.17)$ & $0.13(0-0.18)$ & \\
\hline \multirow[t]{2}{*}{$\mathrm{AD}(\mu \mathrm{g} / \mathrm{kg} / \mathrm{min})$} & Non-ECMO group & $0.001(0-0)$ & $0(0-0)$ & $0.001(0-0)$ & $0.001(0-0)$ & $0.004(0-0)$ & 0.162 \\
\hline & ECMO group & $0.006(0-0)$ & $0.004(0-0)$ & $0(0-0)$ & $0(0-0)$ & $0.013(0-0)$ & \\
\hline \multirow[t]{2}{*}{ Milrinone ( $\mu \mathrm{g} / \mathrm{kg} / \mathrm{min})$} & Non-ECMO group & $0.2(0-0.4)$ & $0.2(0-0.4)$ & $0.2(0-0.4)$ & $0.2(0-0.4)$ & $0.2(0-0.4)$ & 0.580 \\
\hline & ECMO group & $0.1(0-0.2)$ & $0.2(0-0.5)$ & $0.2(0-0.5)$ & $0.2(0-0.5)$ & $0.2(0-0.5)$ & \\
\hline \multirow[t]{2}{*}{ Olprinone $(\mu \mathrm{g} / \mathrm{kg} / \mathrm{min})$} & Non-ECMO group & $0.004(0-0)$ & $0.1(0-0)$ & $0.05(0-0)$ & $0.05(0-0)$ & $0.05(0-0)$ & 0.847 \\
\hline & ECMO group & $0.003(0-0)$ & $0.1(0-0)$ & $0.10(0-0.3)$ & $0.10(0-0.3)$ & $0.08(0-0.2)$ & \\
\hline
\end{tabular}

Data are presented as mean (1st quartile-3rd quartile)

VIS vasoactive inotrope score, $C P B$ cardiopulmonary bypass, $D O A$ dopamine, $D O B$ dobutamine, $N A D$ noradrenaline, $A D$ adrenaline

a compared between the non-ECMO group and the ECMO group

was significantly different between the groups $(p=0.044)$. Figure 1 shows the VIS for both groups; an independent $t$-test revealed that the VIS was significantly higher in ECMO group at $30 \mathrm{~min}$ after CPB $(p=0.03), 60 \mathrm{~min}$ after $\mathrm{CPB}(p=0.003)$, and at the end of the surgery $(p<0.001)$. Figure 2 shows the noradrenaline dose for both groups during LVAD implantation surgery; an independent $t$-test revealed that the doses of noradrenaline were significantly higher in ECMO group at $60 \mathrm{~min}$ after CPB $(p=0.013)$, and the end of surgery $(p=0.002)$.

\section{Discussion}

Patients who received ECMO support prior to LVAD implantation required significantly more vasopressor support compared with those who did not receive preoperative ECMO support. This was most likely caused by the patients' low systemic vascular resistance concomitant with the occurrence of SIRS during ECMO (Mc et al. 2010).

Although the pathophysiology is not completely understood, previous studies have revealed that cardiac surgery using CPB induces SIRS (Cremer et al. 1996; Laffey et al. 2002; Delannoy et al. 2009). Inflammatory mediators are activated and released from blood cells as a result of exposure to the artificial surfaces of the extracorporeal circuit, surgical trauma, hypothermia, and tissue ischemia-reperfusion (Belhaj 2012; Kozik and Tweddell 2006). Cytokines play an important part in the 


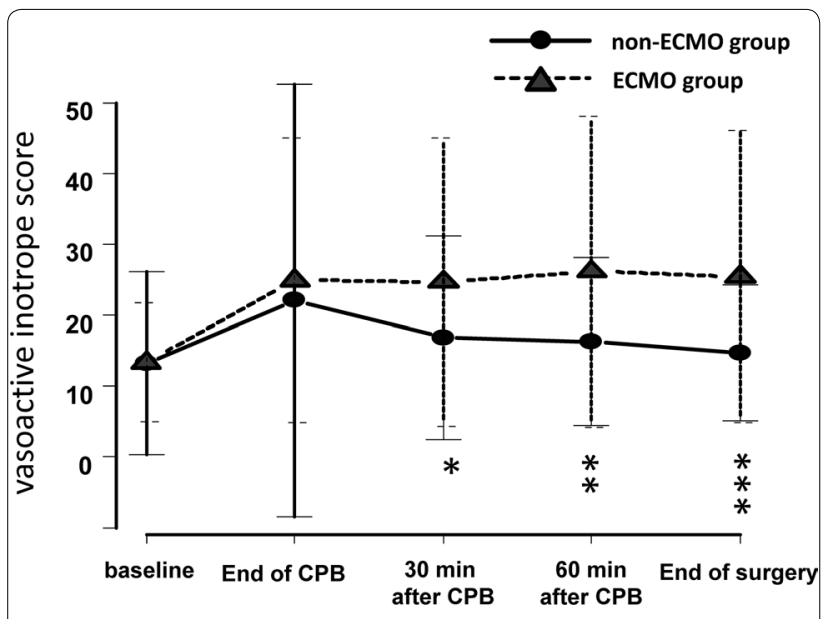

Fig. 1 Change in vasoactive inotrope score during left ventricular assist device implantation in patients who received extracorporeal membrane oxygenation (ECMO) compared with those who did not. All data are expressed as mean (filled symbols) \pm SD (bars). The filled circles and solid line represents the non-ECMO group, and the filled triangles and dotted line represents the ECMO group. ECMO extracorporeal membrane oxygenation, CPB cardiopulmonary bypass. ${ }^{*} p<0.05,{ }^{* *} p<0.01,{ }^{* * *} p<0.001$

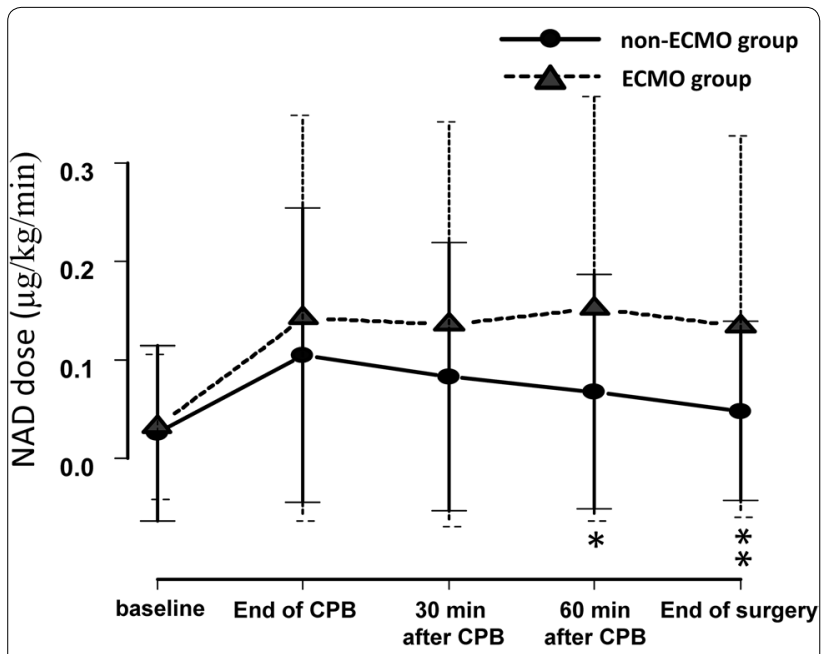

Fig. 2 Change in noradrenaline dose required during left ventricular assist device implantation in patients who received extracorporeal membrane oxygenation (ECMO) compared with those who did not. All data are expressed as mean (filled symbols) \pm SD (bars). The filled circles and solid line represents the non-ECMO group, and the filled triangles and dotted line represents the ECMO group. ECMO extracorporeal membrane oxygenation, NAD noradrenaline, CPB cardiopulmonary bypass. ${ }^{*} p<0.05,{ }^{* *} p<0.01$

inflammatory reaction caused by surgical trauma; they mediate the local inflammatory response, resulting in systemic changes (Gozdzik et al. 2014).

Although there are some pathophysiological differences between $\mathrm{CPB}$ and $\mathrm{ECMO}$, almost all patients treated with ECMO are associated with SIRS, which is characterized by a "cytokine storm", leukocyte activation, and multisystem organ dysfunction (Mc et al. 2010; Chen et al. 2013). An animal model study revealed that animals given ECMO support develop tachycardia and hypotension within 1-2 h of ECMO initiation (Mc et al. 2010).

In our study, patients who received preoperative ECMO support needed more vasopressor to maintain normal MAP levels. This may indicate that hypotension is enhanced by the synergetic effect of the cytokine storm caused by ECMO and CPB. The baseline VIS (before induction of anesthesia) was not different between the groups; therefore, the synergetic effect of both ECMO and CPB may have decreased systemic vascular resistance, which resulted in more vasopressor being required to maintain blood pressure. In the current study, serum total bilirubin, serum creatinine, and serum BUN were significantly higher in the ECMO group; this may reflect that patients who required ECMO support did not recover from preoperative end-organ dysfunction because of cardiogenic shock. Preoperative white blood cell count and serum C-reactive protein level were also significantly higher in the ECMO group, suggesting that preoperative SIRS induced by ECMO may have an impact on hemodynamics. Bertrand et al. investigated the association between biological markers and CPBinduced SIRS. They found that baseline C-reactive protein is significantly higher in patients with SIRS than in patients without SIRS (6.7 vs $1.8 \mathrm{mg} / \mathrm{l}, p=0.016$ ) (Delannoy et al. 2009). This agrees with our result in which the baseline C-reactive protein was significantly higher in the ECMO group, who needed more vasopressor because of SIRS induced by ECMO and CPB.

In our study, inotropes, vasopressors, and vasodilators were administered at the discretion of the individual attending anesthesiologist, depending on the hemodynamics and real-time transesophageal echocardiography. However, there was no difference between the groups in terms of the hemodynamic parameters such as MAP, CVP, SVRI, and SvO2. It follows that the target hemodynamics were the same in both groups. Each attending anesthesiologist used noradrenaline as a vasopressor to maintain systemic vascular resistance within normal range. However, we were unable to determine whether this method of vasopressor use improved the outcome of the patients who had received preoperative ECMO support. Few studies to date have demonstrated a significant survival benefit of one vasopressor over another. Further study is necessary to demonstrate that the use of a vasopressor can improve the outcome of patients after LVAD implantation.

There were some limitations to this study. First, the number of patients was relatively small. We conducted 
a power analysis to determine the minimum number required for each group. Because no previous studies comparable to ours have been conducted, we empirically designated the difference in the VIS means as eight. The variance of VIS was computed based on the VIS variance of the first 20 patients. Although we conducted a power analysis, it is possible that the ideal sample size is larger than presented here because of the empirical process. Second, this study was retrospective and the accuracy of chart documentation cannot be guaranteed. Besides, we cannot eliminate the other multiple factors affecting vasodilatory responses other than ECMO, including multi-organ failure, use of IABP, mechanical ventilation, possibly intraoperative blood loss or dosage of phosphodiesterase inhibitor. Third, the coefficient of olprinone in modified VIS may be inaccurate because it was defined based on the study with small number of patients. Finally, this was a single-center study, and thus our findings may not be generalizable to other patient populations.

\section{Conclusions}

In conclusion, patients supported by ECMO prior to LVAD implantation required significantly more noradrenalineto maintain normal hemodynamic parameters compared with patients without ECMO.

\section{Authors' contributions}

TM and KT carried out this study. TM wrote the manuscript and performed statistical analysis. SM, KM and OY participated in the design of the study. All authors read and approved the final manuscript.

\footnotetext{
Author details

1 Department of Anesthesiology, National Cerebral and Cardiovascular Center, 5-7-1 Fujishirodai, Suita, Osaka 565-8565, Japan. ${ }^{2}$ Department of Cardiovascular Surgery, Osaka University Graduate School of Medicine, 2-2 Yamada-oka, Suita, Osaka 565-0871, Japan. ${ }^{3}$ Division of Transfusion Medicine, National Cerebral and Cardiovascular Center, 5-7-1 Fujishirodai, Suita, Osaka 565-8565, Japan.
}

\section{Competing interests}

The authors received a grant-in-aid from the Takeda Science Foundation to cover the publication fee.

Received: 2 October 2015 Accepted: 21 December 2015

Published online: 30 December 2015

\section{References}

Belhaj A (2012) Actual knowledge of systemic inflammation reaction during cardiopulmonary bypass. Recent Pat Cardiovasc Drug Discov 7(3):165-169

Chen Q, Yu W, Shi J, Shen J, Hu Y, Gao T, Zhang J, Xi F, Gong J, Li J, Li N (2013) The effect of venovenous extra-corporeal membrane oxygenation (ECMO) therapy on immune inflammatory response of cerebral tissues in porcine model. J cardiothorac Surg 8:186. doi:10.1186/1749-8090-8-186
Cremer J, Martin M, Redl H, Bahrami S, Abraham C, Graeter T, Haverich A, Schlag G, Borst HG (1996) Systemic inflammatory response syndrome after cardiac operations. The Ann Thorac Surg 61(6):1714-1720. doi:10.1016/0003-4975(96)00055-0

Delannoy B, Guye ML, Slaiman DH, Lehot JJ, Cannesson M (2009) Effect of cardiopulmonary bypass on activated partial thromboplastin time waveform analysis, serum procalcitonin and C-reactive protein concentrations. Crit Care 13(6):R180. doi:10.1186/cc8166

Gaies MG, Gurney JG, Yen AH, Napoli ML, Gajarski RJ, Ohye RG, Charpie JR, Hirsch JC (2010) Vasoactive-inotropic score as a predictor of morbidity and mortality in infants after cardiopulmonary bypass. Pediatr Crit Care Med 11(2):234-238. doi:10.1097/PCC.0b013e3181b806fc

Gozdzik W, Adamik B, Gozdzik A, Rachwalik M, Kustrzycki W, Kubler A (2014) Unchanged plasma levels of the soluble urokinase plasminogen activator receptor in elective coronary artery bypass graft surgery patients and cardiopulmonary bypass use. PLoS One 9(6):e98923. doi:10.1371/journal. pone.0098923

Holman WL, Kormos RL, Naftel DC, Miller MA, Pagani FD, Blume E, Cleeton T, Koenig SC, Edwards L, Kirklin JK (2009) Predictors of death and transplant in patients with a mechanical circulatory support device: a multiinstitutional study. J Heart Lung Transplant 28(1):44-50. doi:10.1016/j. healun.2008.10.011

Kanda Y (2013) Investigation of the freely available easy-to-use software 'EZR' for medical statistics. Bone Marrow Transplant 48(3):452-458. doi:10.1038/bmt.2012.244

Kozik DJ, Tweddell JS (2006) Characterizing the inflammatory response to cardiopulmonary bypass in children. Ann Thorac Surg 81(6):S2347-2354 doi:10.1016/j.athoracsur.2006.02.073

Laffey JG, Boylan JF, Cheng DC (2002) The systemic inflammatory response to cardiac surgery: implications for the anesthesiologist. Anesthesiology 97(1):215-252

Mc IRB, Timpa JG, Kurundkar AR, Holt DW, Kelly DR, Hartman YE, Neel ML, Karnatak RK, Schelonka RL, Anantharamaiah GM, Killingsworth CR, Maheshwari A (2010) Plasma concentrations of inflammatory cytokines rise rapidly during ECMO-related SIRS due to the release of preformed stores in the intestine. Lab Invest 90(1):128-139. doi:10.1038/labinvest.2009.119

Orime Y, Shiono M, Hata H, Yagi S, Tsukamoto S, Okumura H, Kimura S, Hata M, Sezai A, Obana M, Sezai Y (1999) Effects of phosphodiesterase inhibitors after coronary artery bypass grafting. Jpn Circ J 63(2):117-122

Rao V, Oz MC, Flannery MA, Catanese KA, Argenziano M, Naka Y (2003) Revised screening scale to predict survival after insertion of a left ventricular assist device. J Thorac Cardiovasc Surg 125(4):855-862. doi:10.1067/ mtc.2003.111

Toda K, Fujita T, Kobayashi J, Shimahara Y, Kitamura S, Seguchi O, Murata Y, Yanase M, Nakatani T (2012) Impact of preoperative percutaneous cardiopulmonary support on outcome following left ventricular assist device implantation. Circ J 76(1):88-95

\section{Submit your manuscript to a SpringerOpen ${ }^{\circ}$ journal and benefit from: \\ - Convenient online submission \\ - Rigorous peer review \\ - Immediate publication on acceptance \\ - Open access: articles freely available online \\ - High visibility within the field \\ - Retaining the copyright to your article}

Submit your next manuscript at $>$ springeropen.com 